International Journal of Research in Engineering and Innovation
(IJREI)

\title{
Optimization of supplementary cementitious materials volume in concrete
}

\author{
Kailash Kumar' ${ }^{1}$ Noorul Bashar ${ }^{2}$ \\ ${ }^{1} M$. Tech Student, Department of Civil Engineering, VCTM, Aligarh, AKTU Lucknow \\ ${ }^{2}$ Assistant Professor, Department of Civil Engineering, VCTM Aligarh, AKTU Lucknow
}

\begin{abstract}
To study the effect of partial replacement of cement by binary blend of supplementary cementitious materials (SCM), studies have been conducted on concrete mixes with 300 to $450 \mathrm{~kg} / \mathrm{cum}$ cementitious material at $10-30 \%$ replacement levels for fly ash, metakaolin and silica fumes. In the present study it is planned to conduct lab investigation by preparing mono, binary, ternary blends of silica fume, fly ash and metakaolin (10\% content for each while replacing cement content by volume) for M30 grade of concrete. The importance of this investigation is to utilize the maximum percentage of considered SCMs in concrete mixes and to minimize the content of virgin materials. The major objectives include studying the compressive, split tensile and flexural strengths after judging workability of SCM mortar while comparing it with conventionally used normal concrete. The study also involves finding the optimum dosage of SCMs which gives maximum strength when compared to normal conventional concrete. The test results of this research work indicates that at fixed water cement ratio, workability in terms of compaction factor decreased with the use of considered SCMs as a replacement of cement in concrete. Compressive, tensile and flexural strengths for SCM concrete having fly ash and silica fumes at the curing age of 7 and 28 days were comparable to conventional concrete at a cement replacement of up to $20 \%$.

(C)2020 ijrei.com. All rights reserved

Keywords: Silica fume, fly Ash, metakaolin, concrete, compressive and tensile testing
\end{abstract}

\section{Introduction}

Concrete is the most utilized constructional material on the planet. Cement is the fundamental binding material used in concrete. In the course of recent decades, the production of cement has grown quickly everywhere throughout the world economies. The cement production in India is relied upon to grow three-folds by 2050 [1]. Notwithstanding, cement creation has major ecological issues that are of concern around the world. For each one ton of clinker fabricated, roughly one ton of $\mathrm{CO}_{2}$ is discharged to the air which contributes very nearly $5-7 \%$ of worldwide anthropogenic carbon dioxide emanations. In the manufacturing procedure of cement, the principles wellsprings of gas outflows are burning of energize and decay of $\mathrm{CaCO}_{3}$ to $\mathrm{CaO}$ and $\mathrm{CO}_{2}$ [2] Beneficial cementitious materials are utilized to in part supplant clinker, which in the long run decreases these harmful emissions. Three essential blend proportioning strategies have been commonly utilized for valuable cementitious materials mixed concrete systems. These are: (1) the partial substitution of cement, i.e. the basic substitution technique; (2) the addition of SCMs as fine aggregate, the addition strategy; and, (3) the partial substitution of cement, fine aggregate, and water. A variety of the main strategy is to supplant cement by SCMs by weight and decrease the water substance to acquire equivalent usefulness. The simple substitution strategy requires direct replacement of a segment of the Portland cement with SCMs either on a weight or volume premise. Supplementary cementitious materials (SCMs) are materials that can be used to partially replace clinker in cements. They are generally by-products of industrial or other processes. Some natural materials, with or without processing, can also be used as SCMs. Though SCMs do not have cementitious properties by themselves, they hydrate with the hydration products of cement or in the presence of cement to produce additional C-S-H and other hydration products. This reaction is generally known as the pozzolanic reaction and such materials are also known as pozzolans. Some of the commonly used SCMs are ground granulated blast furnace slag, fly ash, silica fume, metakoalin, and rice husk ash. SCMs can be used to improve the performance of concrete in its fresh and hardened 
state. The reaction of SCMs is dependent on the $\mathrm{pH}$ and temperature in the pore solution and their reactivity is generally higher at higher alkalinities and temperatures [3,4]. Despite studies showing the benefits of Indian SCMs [5] and Indian standards allowing up to $35 \%$ replacement of cement by fly ash, the majority of fly ash available in India still goes to landfills. This is mainly because of the unpredictability in the development of mechanical properties of fly ash due to large variation in their compositions of fly ashes around the world and the lack of awareness about the potential advantages of mixing fly ash in concrete. However, some authors have questioned the benefits of Indian fly ashes, which are known to be less reactive than fly ashes elsewhere [6]. Concrete can serve as the safest home of fly ash, metakaolin, and silica fumes having a tremendous Potential for its utilization. Compare to the conventional concrete mixture, the SCM concrete system requires one third less mixing water. As a result, not only the w/c ratio of the SCM concrete is lower but also total volume of the cement paste is nearly $16 \%$ less. SCM concrete generates nearly $40 \%$ less heat of hydration at early age therefore, in massive structural members the potential for thermal shrinkage and cracking is also greatly reduced.

The main aim of this research is to study the effect of mechanical characteristics of Fly Ash, metakaolin and silica fumes on compressive, split tensile strengths and workability of concrete. The objectives of this work are listed below:

- To understand which considered SCM and its characteristics affects more on compressive strength development in mortar.

- To understand which considered SCM and its characteristics affects more on split tensile strength development in mortar.

- To understand which considered SCM and its characteristics affects more on workability in mortar.

- To optimize the volumetric content of SCMs in concrete as partial replacement of cement particles resulting better performance.

\section{Experimentation Methodology}

The main ingredients for SCM concrete are almost the same as that of conventional concrete with addition of other SCMs mentioned as follows: 1 . Cement, 2. Fine aggregate, 3. Course aggregate, 4. Water, and 5. Supplementary Cementitious Materials (Fly ash, metakaolin and silica fumes)

Ordinary Portland cement 53 grade confirming to IS: 122692009 [7] was used in this investigation. The fine aggregate (sand) confirming to zone II and crushed stone of nominal size $20 \mathrm{~mm}$ of IS $383-1970$ were used for making concrete. Potable water has been used for mixing the concrete and to cure the cast specimens. The fly ash of class ' $F$ ' obtained from Kasimpur thermal power station, Aligarh, Uttar Pradesh is used to cast the cube, Cylinders and beams for calculating the compressive, split tensile and flexural strength [8]. The percent replacement of

cement particles with considered SCMs is shown in Table 1. Cube specimens were cast with dimensions of $150 \mathrm{~mm} \mathrm{x}$ $150 \mathrm{~mm} \times 150 \mathrm{~mm}$ for quantifying $7^{\text {th }}$ and $28^{\text {th }}$ day compressive strength, and cylindrical specimens with dimensions of $150 \mathrm{~mm}$ diameter $\times 300 \mathrm{~mm}$ length for finding $7^{\text {th }}$ and $28^{\text {th }}$ days indirect tensile strength experimentally. The numbers of specimens used for this research are 48 cubes for compressive strength tests, 48 cubes; 48 cylinders for indirect tensile strength tests, 24 prisms for flexural strength test. The methodology for concrete mixing involved the following. Firstly, the aggregates and sand were washed with water and completely dried. Then both were placed in the concrete mixer and dry mixed for 2 minutes. Then, cement and SCMs were added in the mixer with aggregates and sand and dry mixed for 2 minutes. Then admixtures were added and dry mixed for 1 minute. Then normal water $(85 \%)$ is added and mixed for approximately 2 minutes. Remaining mixing water $(15 \%)$ were added to the mixer and mixed for 3 minutes. Then the mixed concrete was cast into the specimen moulds and vibrated simultaneously in the vibrator for 1 minute to remove any air remaining entrapped mainly to avoid voids. Each specimen was allowed to stand for 24 hours in concrete laboratory before de-moulding.

Table 1: Proportioning of concrete mixes

\begin{tabular}{|c|c|c|c|}
\hline Mix Grade & Fly Ash & Metakaolin & Silica fume \\
\hline Conventional (Mix-0) & 0 & 0 & 0 \\
\hline Mix-1 & 10 & 0 & 0 \\
\hline Mix-2 & 0 & 10 & 0 \\
\hline Mix-3 & 0 & 0 & 10 \\
\hline Mix-4 & 10 & 10 & 0 \\
\hline Mix-5 & 0 & 10 & 10 \\
\hline Mix-6 & 10 & 0 & 10 \\
\hline Mix-7 & 10 & 10 & 10 \\
\hline
\end{tabular}

The following experiments are conducted on the specimen casted at VCTM, Aligarh

(i)

(ii)

(iii)

(iv)

\section{Compression Test}

\section{Split tensile Test or Indirect Tensile Test}

Flexural strength test

Workability Test

For finding the compressive strength, casting of concrete cubes of $150 \mathrm{~mm} \times 150 \mathrm{~mm} \times 150 \mathrm{~mm}$ size was carried out using pre oiled moulds. The test specimens were divided into eight groups. Each group consist of partial replacement of cement by binary and ternary blends having $10 \%$ considered SCMs. Cube specimens were cast for 7 and 28 days curing period. All the specimens were de-moulded after 24 hours and cured in water. The water or solution in which the specimens are kept should be renewed every seven days and should be maintained at a temperature of $27^{\circ}+/-2^{\circ} \mathrm{C}$. The specimens were dried in air for one day before testing under compression testing machine. 
Table 2: Design Mix results for different percentage of SCM in concrete.

\begin{tabular}{|c|c|c|c|c|c|c|c|c|}
\hline $\begin{array}{l}\text { Grade of Concrete } \\
\text { with Replacement } \\
\text { percentage of SCM }\end{array}$ & $\begin{array}{c}\text { Cement } \\
\text { Composition } \\
\left(\mathrm{Kg} / \mathrm{m}^{3}\right)\end{array}$ & $\begin{array}{c}\text { Sand } \\
\text { Composition } \\
\left(\mathrm{Kg} / \mathrm{m}^{3}\right)\end{array}$ & $\begin{array}{c}\text { Coarse Aggregate } \\
\text { Unit weight } \\
\left(\mathrm{Kg} / \mathrm{m}^{3}\right)\end{array}$ & $\begin{array}{c}\text { Fly ash Unit } \\
\text { weight } \\
\left(\mathrm{Kg} / \mathrm{m}^{3}\right)\end{array}$ & $\begin{array}{l}\text { MK unit weight } \\
\left(\mathrm{Kg} / \mathrm{m}^{3}\right)\end{array}$ & $\begin{array}{c}\text { Silica unit } \\
\text { weight } \\
\left(\mathrm{Kg} / \mathrm{m}^{3}\right)\end{array}$ & $\begin{array}{l}\text { W/C } \\
\text { Ratio }\end{array}$ & $\begin{array}{c}\text { Water } \\
\text { Used } \\
\text { (Litres) }\end{array}$ \\
\hline \multicolumn{9}{|l|}{ M30 } \\
\hline Conventional $(0 \%)$ & 457.32 & 696.16 & 1138.249 & 0 & 0 & 0 & 0.45 & 205 \\
\hline $10 \%$ & 411.59 & 696.16 & 1138.249 & 45.73 & 0 & 0 & 0.45 & 205 \\
\hline $10 \%$ & 411.59 & 696.16 & 1138.249 & 0 & 45.73 & 0 & 0.45 & 205 \\
\hline $10 \%$ & 411.59 & 696.16 & 1138.249 & 0 & 0 & 45.73 & 0.45 & 205 \\
\hline $20 \%$ & 365.86 & 696.16 & 1138.249 & 45.73 & 45.73 & 0 & 0.45 & 205 \\
\hline $20 \%$ & 365.86 & 696.16 & 1138.249 & 0 & 45.73 & 45.73 & 0.45 & 205 \\
\hline $20 \%$ & 365.86 & 696.16 & 1138.249 & 45.73 & 0 & 45.73 & 0.45 & 205 \\
\hline $30 \%$ & 320.12 & 696.16 & 1138.249 & 45.73 & 45.73 & 45.73 & 0.45 & 205 \\
\hline
\end{tabular}

The indirect tensile strength test was carried out in accordance with Indian standards code using UTM machine with a loading capacity of $1000 \mathrm{kN}$ and a loading rate of $1 \pm 0.1 \mathrm{MPa} /$ minute provided with indirect tensile strength test equipment [12]. A standard test cylinder of concrete specimen $(300 \mathrm{~mm} \times 150 \mathrm{~mm}$ diameter) is placed horizontally between the loading surfaces of compression testing machine.

The compression load is applied diametrically and uniformly along the length of cylinder until the failure of cylinder along the vertical diameter. In both the above mentioned tests, three specimens for each batch were tested at the age of $7^{\text {th }}$ and $28^{\text {th }}$ days after casting. The average results of the three cylindrical or cubic specimens are reported as its final tensile or compressive strengths. Experimental set up for destructive testing was planned to study the flexural strength on the standard moulds confirming to IS: 456-2000 [9].

Flexure strength test values are obtained after testing the concrete prism for each concrete mix grade under flexural strength test. All the specimens of normal concrete and SCM concrete were wet cured for 28 days at room temperature and were tested on $1000 \mathrm{KN}$ Universal testing machine (UTM). Flexural test was carried on beams of size $150 \mathrm{~mm}$ x $150 \mathrm{~mm} \times$ $500 \mathrm{~mm}$ size $[10,11]$. The test specimens were divided into eight groups. Each group consist of partial replacement of cement by SCM at $0,10 \%, 20 \%$, and $30 \%$. All the specimens were demoulded after 24 hours and cured in water. The specimens were dried in air for one day before testing. Each test was carried out in triplicate and results were averaged and recorded.

Compacting factor of fresh concrete is done to determine the workability of fresh concrete by compacting factor test as per IS: 1199 - 1959. The apparatus used is Compacting factor apparatus.

\section{Results and discussion}

The average compressive strength results of M30 grade conventional concrete as well as for concrete having replacements of binary and ternary blends of SCM concrete at $7^{\text {th }}$ and $28^{\text {th }}$ day is given by Figure 1 and Figure 2.

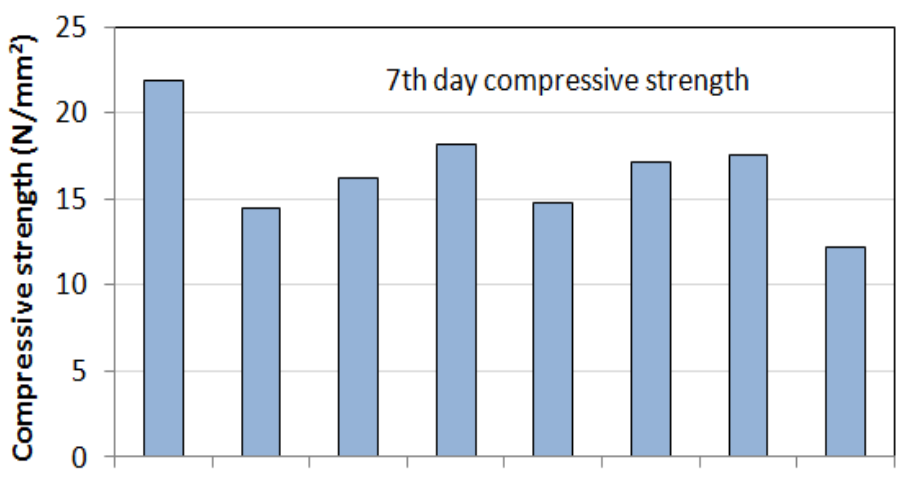

Mix-0 Mix-1 Mix-2 $\quad$ Mix-3 $\quad$ Mix-4 $\quad$ Mix-5 $\quad$ Mix-6 $\quad$ Mix-7

Mix Grade of SCM concrete

Figure 1: Variation of Compressive strength with increasing percent of binary and ternary blends SCMs replaced with cement for M30 Grade concrete mixes at 7 day curing

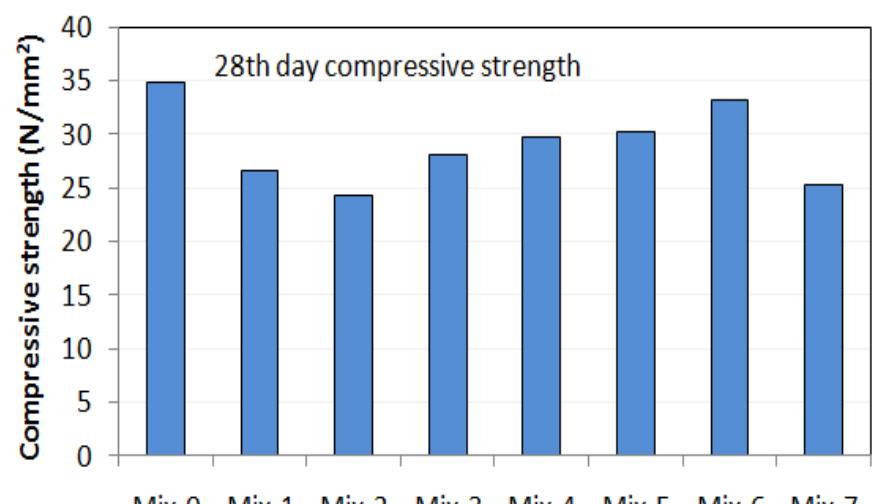

Mix-0 Mix-1 Mix-2 Mix-3 Mix-4 Mix-5 Mix-6 Mix-7

Mix Grade of SCM concrete

Figure 2: Variation of Compressive strength with increasing percent of binary and ternary blends SCMs replaced with cement for M30 Grade concrete mixes at 28-day curing. 


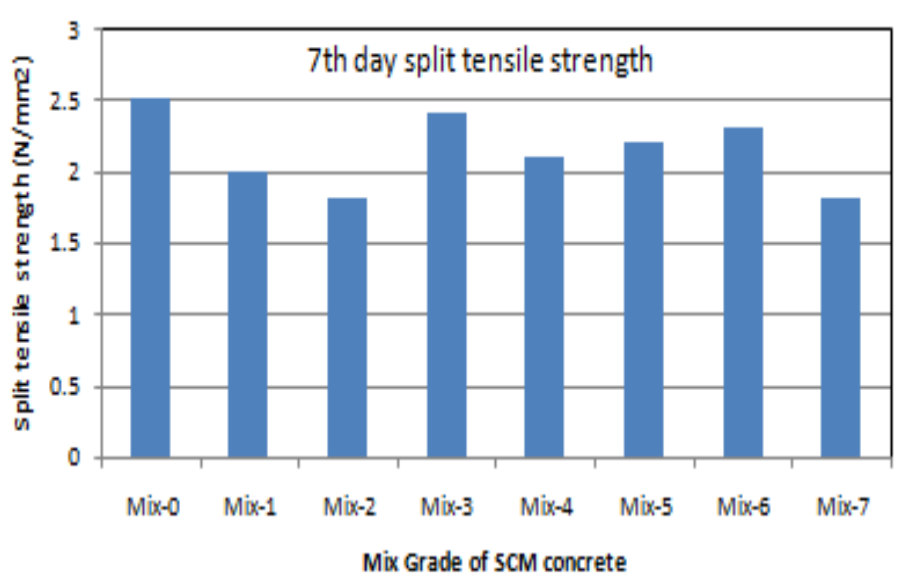

Figure 3: Variation of split tensile strength with increasing percent of binary and ternary blends SCMs replaced with cement for M30 Grade concrete mixes at 7-day curing.

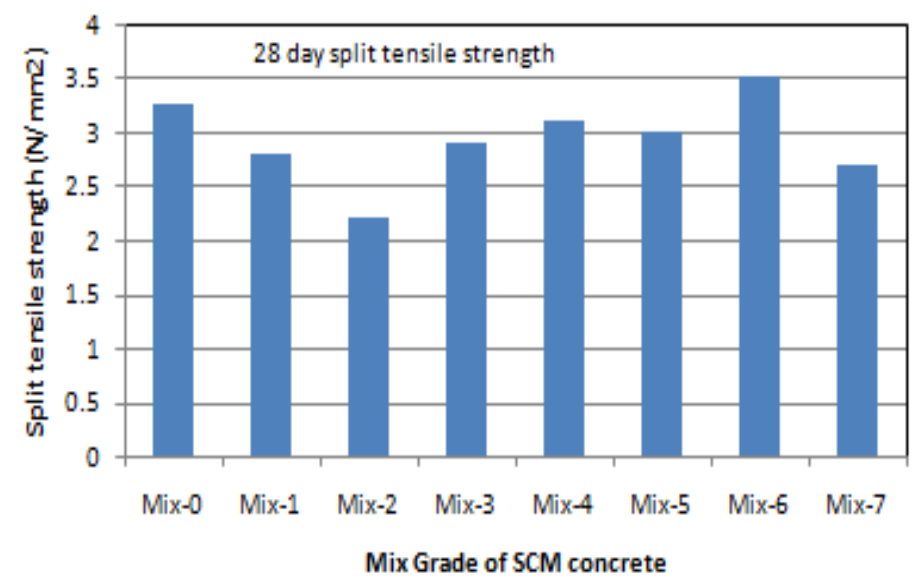

Figure 4: Variation of split tensile strength with increasing percent of binary and ternary blends SCMs replaced with cement for M30 Grade concrete mixes at 28-day curing.

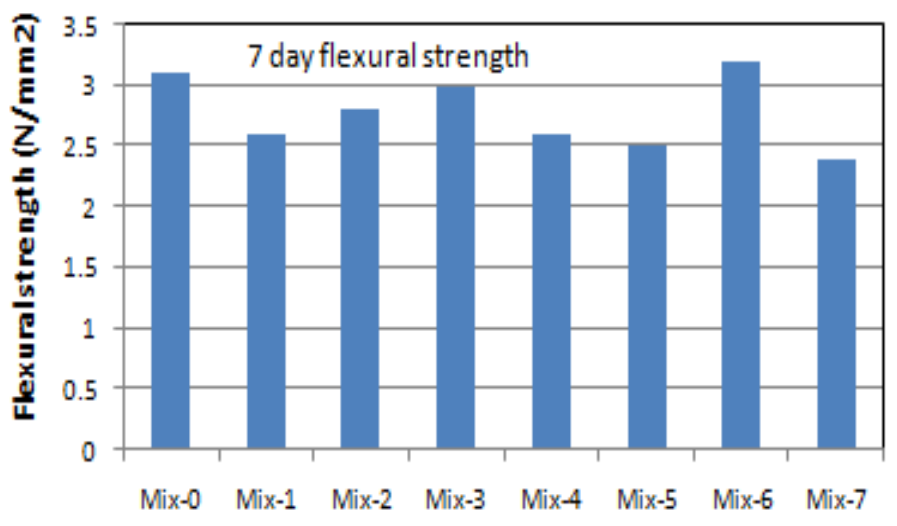

Mix Grade of SCM concrete

Figure 5: Variation of flexural strength with increasing percent of binary and ternary blends SCMs replaced with cement for M30 Grade concrete mixes at 7-day curing.

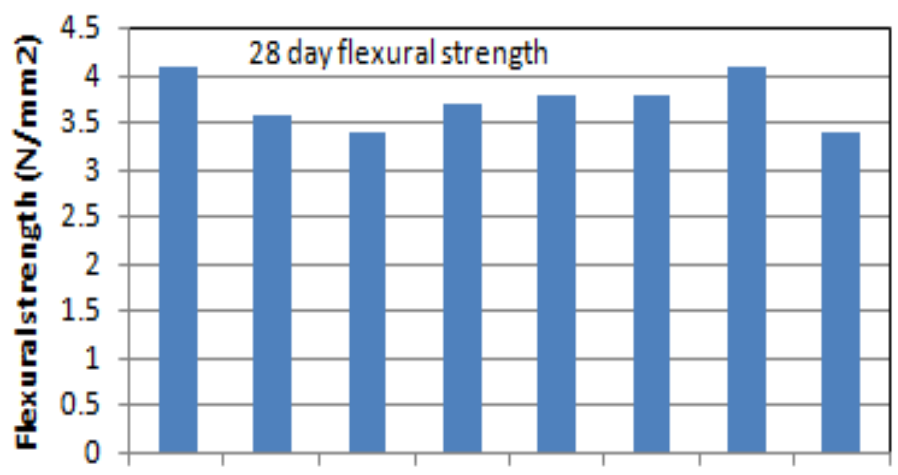

Mix-0 Mix-1 Mix-2 Mix-3 Mix-4 Mix-5 Mix-6 Mix-7

Mix Grade of SCM concrete

Figure 6: Variation of flexural strength with increasing percent of binary and ternary blends SCMs replaced with cement for M30 Grade concrete mixes at 28-day curing.

The workability is measured in terms of compaction factor, which is defined as the ratio of weight of partially compacted concrete to the weight of fully compacted concrete, decreases with the increase of the replacement level of the cement with the SCM. It can be due to the extra fineness of SCM as the replacement level of cement particles increased. Thus, increase in the specific surface due to increased fineness and a greater amount of water needed for the mix ingredients to get closer packing, results in decrease in workability of mix.

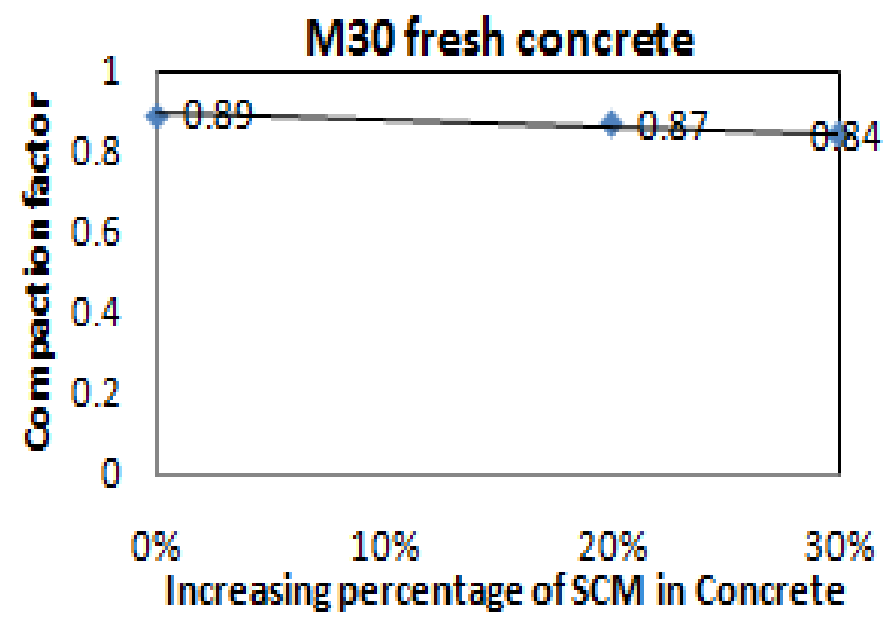

Figure 7: Variation of compaction factor to increasing percentage of SCM in concrete

\section{Conclusions and Future scope}

From the present research study, the successful effect of partial replacement of cement by SCM on strength and workability parameters has been depicted. The experimentations have been conducted on concrete mixes with 250 to $450 \mathrm{~kg} / \mathrm{cum}$ cementitious material at 10\%,20\%, and 30\% binary and ternary replacement levels in concrete of grade M30. The investigation 
is made to utilize the maximum percent of SCMs in concrete mixes and to minimize the mining of virgin materials. The following conclusions are depicted from the present study:

- Compressive, split tensile and flexural strength and Workability test on specimens with different volume of supplementary cementitious material (SCM) concrete has been observed and compared with that of normal conventional concrete.

- Study for the optimum dosage of SCM which gives maximum compressive strength compared to normal conventional concrete is done.

- The test results of this research work indicates that at fixed water cement ratio, workability in terms of compaction factor decreased with the use of SCM as a replacement of Cement in concrete.

- The trends for compressive strength, Tensile strength, workability and flexural strength are generated with different percentage of SCM concrete.

- Compressive strength of binary mix having $10 \%$ each of fly ash and silica fumes at the curing age of 7 and 28 days was comparable to conventional concrete up to a replacement with SCM up to $20 \%$. It is concluded that Partial replacement of cement by silica fumes gives positive impact on the compressive strength.

- Splitting tensile strength of concrete improved at percentages of replacement of SCM. Percentage replacement of considered SCM above 20\% adversely affects the tensile strength of concrete.

- Workability in terms of compaction factor slightly decreased with increment of SCM content.

- From the results, it is found that $20 \%$ is the optimum content of SCM (having $10 \%$ each of fly ash and silica fume) in the concrete.

- From the study, the fly ash, metakaolin and silica fumes can be considered as resource material and can be used in productive way contributing to sustainable development.

The future scope of the present research may include the following:

- Evaluation of Long-term mechanical, micro-structural and chemical properties of SCM concrete may be evaluated to depict more clear representation of performance of supplementary cementitious materials in cement concrete as done for other mixes in literature $[12,13]$.

- Statistical analysis may be performed on higher number of experimental data sets after performing regression or Anova test. The sets of equations may help in depicting the strength parameters for different SCM concrete mixes at any curing time having their dependency on percentage replacements [14].

- Analytical and numerical validation of the study can also be performed after developing finite element models in future.

- Use of other SCMs as a partial replacement of cement or aggregate can also be done for optimising volumetric fraction to make concrete sustainable to environment.

\section{References}

[1] Concrete technology (M L Gambhir).

[2] V. M. Malhotra and P. K. Mehta: High-Performance High-Volume Fly Ash Concrete: Materials, Mixture Proportioning, Properties, Construction practice.

[3] Mukesh Kumar, Umesh. K.Kakkar, N.P.Singh, Sanjay Singh and N.B.Singh, "Concrete properties in the presence of fly ash, super plasticise and crystalline water proofing compound". The Indian concrete Journal, December 2011.

[4] Rafat Siddique, "Performance characteristics of high volume class F fly ash concrete" Cement and Concrete Research 34 (2004).

[5] Chung-Ho Huang, Shu-ken Lin, Chao-Shun Chang, How-Ji Chen. (2013, April). Mix propotioons and mechanical properties of concrete containing very high-volume of Class $\mathrm{F}$ fly ash. ScienceDirect. Construction and Building Materials. [Online]. 46, pp. 71-78.

[6] Faiz U.A. Shaik, Steve W.M. Supit, (2014). Mechanical and durability properties of high volume fly ash (HVFA) concrete containing calcium carbonate $(\mathrm{CaCO} 3)$ nanoparticles. ScienceDirect. Construction and Building Materials. [Online]. 70,pp.309-321.

[7] Indian standard concrete mix proportioning guidelines (first revision) is 10262-2009, bureau of Indian standard New Delhi.

[8] Mahdi Arezoumandi, Jeffery S.Volz, Carlos A.Ortega, John J.Myers. (2012, November). Effect of total cementitious content on shear strength of high-volume fly ash concrete beams. ScienceDirect. Materials and Design. [Online]. 46, pp. 301-309.

[9] Code of practice for plain and reinforced concrete (fourth edition), IS 4562000, bureau of Indian standard New Delhi.

[10] P.Nath, P.Sarker. (2011). Effect of Fly Ash on the Durability properties of High Strength Concrete. ScienceDirect. Procedia Engineering. [Online]. 14, pp. 1149-1156.Available: www.elsevier.com/locate/procedia

[11] Obada Kayali, M.Sharfuddin Ahmed. (2012, May). Assesment of high volume replacement fly ash concrete - Concept of performance index. SceinceDirect. Construction and Building Materials. [Online]. 39, pp. 7176.

[12] Shi, C., Wang, D., Wu, L., and Wu, Z. (2015). "The hydration and microstructure of ultra high strength concrete with cement-silica fumeslag binder." Cement and Concrete Composites, 61, 44-52.

[13] Sharma, P., and Tyagi, D. (2011). "Effect of Blended Fly ash and superplasticizer on Pozzolanic Activity and Compressive Strength of Cement Paste." New Building Material and Construction World, 16.

[14] Shehata, M. H., Thomas, M. D. a., and Bleszynski, R. F. (1999). "The effects of fly ash composition on the chemistry of pore solution in hydrated cement pastes." Cement and Concrete Research, 29(12), 1915-1920.

Cite this article as: Kailash Kumar, Noorul Bashar, Optimization of supplementary cementitious materials volume in concrete,

International Journal of Research in Engineering and Innovation Vol-4, Issue-4 (2020), 207-211.

.https://doi.org/10.36037/IJREI.2020.4404. 